\title{
INFORMATION OVERLOAD REVISITED: INFINITE ORGANIZATIONAL THREATS
}

\author{
Debra J. Borkovich, Middle GA State University, debra.borkovich@mga.edu
}

\begin{abstract}
Coined by Gross (1964) and popularized by Toffler (1970) and Carr (2010), information overload represents an overwhelming bombardment of digital information that often substantiates underpinnings of continuous mental stress, anxiety, and distraction caused by a combination of queued info glut and incessant interruptions. But it was the advent of the World Wide Web in 1989 (Berners-Lee, 2000) and the onset of ubiquitous connectivity that turned information overload into a daunting and even debilitating phenomenon. Informationists have written extensively about the corporate manifestation of info glut in the workplace requiring agile mitigation strategies to retain knowledge workers and managers. And a new Pew Report (Dec. 2016) disclosed positive results that users are discovering their own ways to ameliorate the tensions of today's information-saturated-world when organizations place high demands on employees. However, this research represents a pragmatic approach to understanding the present environment of organizational information overload. The professional employees and managers of a large US global corporation were studied for coping strategy feedback regarding an infinite and unwieldy information glut; results were analyzed for successful or failed remedies set-forth by employers; and then findings were compared to the Pew Report results to assess the current state of infomania (Ferrarini, 1984) in the workplace.
\end{abstract}

Keywords: information overload, infomania, digital agility, context collapse, culture shock

\section{INTRODUCTION}

Humans are the instruments of the Information Age and technology (physical, artificial, sensory, digital, analog, and virtual) provides our tools to manage the glut of data that descends nano-second-by-nano-second upon all of us. We constantly evolve, change, and transform to meet the needs of our organizational customers and stakeholders, because they too, are human creations. IBM estimates that by 2020, at least 44 zettabytes of data, the thousand-fold number next up from exabytes, will be generated from all of our computers and mobile tech devices (Hardy, 2016). Therefore, information overload has been a key topic of subject matter experts for some time. Through the lens' of social scientists, academics, informationists, business management, and communication theorists, this paper discusses how theories and strategies were applied to a US global Fortune 500 organization to mitigate occurrences of digital culture shock engendered from the constant glut of information. Through the interpretation and analysis of pre-existing literature, current knowledge worker observations, and Informant interviews, this author argues that organizational information overload, ever-present and exponentially multiplying may no longer be impossible for some to manage. A Pew Survey (Horrigan, Dec. 2016) of 1,520 US adult Americans reported that only $20 \%$ feel overloaded by information (an improvement from $27 \%$ in 2006), while $77 \%$ like having so much information at their fingertips. Pew's results showed that Americans are more comfortable with their abilities to cope with a deluge of information; therefore, this research explores if knowledge workers and managers are also more comfortable with the construct of information overload within an organizational environment, and have learned ways to mitigate the stress and anxiety with the power to separate the meaningful information from the noisy glut.

This Agile Ethnography was based upon observations, interviews, and Informant conversations with professional employees of a elephantine Fortune 500 corporation at its US Mid-Atlantic subsidiary. The qualitative approach to inquiry was motivated by noted gaps in the literature regarding the application of organizational agile technologies to mitigate or ameliorate information glut in the workplace. The researcher was interested in collecting knowledgeworker and managerial feedback to learn how and why their conceptualizations of information overload helped or hindered employees' accomplishment of daily tasks in the workplace. Results were analyzed and interpreted to refine the findings and develop future recommendations. Not surprisingly, this organization implemented remedies with varying degrees of success. 


\section{LITERATURE REVIEW}

This section presents a limited historical background and relevant literature precipitating the onset of voluminous information glut in the workplace. The resultant constructs of information overload, culture shock, infomania, digital agility, context collapse, satisficing, and bounded rationality are also described as coined and introduced by the theorists; and a summary of the Pew Survey "Information Overload" (Dec. 2016) is offered.

\section{Information Overload \& Culture Shock}

The Digital Age brought us directly to the point of a self-perpetuating information overload that was capable of manifesting itself into a culture shock (Oberg, 1960) of massive proportions. Information overload, a term coined by Gross (1964, p. 856) and popularized by Toffler (1970) and Carr (2010), refers to the difficulty a person can have understanding an issue, determining options, and making decisions that can be caused by the presence of too much information. Shannon (1949) argued that the most important attribute of a message was the information; and Simon (1972) proffered that "bounded rationality" and "satisficing" placed perimeters around the maximum amount of information that a human can process at any time.

Psychologists viewed information overload as a bombardment to the senses, a version of sensory overload, causing confusion, distraction, disorientation and lack of responsiveness. Toffler (1970, pp. 350-351) suggested that: "When the individual is plunged into a fast and irregularly changing situation, or a novelty-loaded context ... his predictive accuracy plummets. He can no longer make the reasonably correct assessments on which rational behavior is dependent." Akin to Toffler's description, individuals' exposure to exponential sources of constant information glut engender overload, long before a person's recognition of the validity of the content or the risk of misinformation.

Postman (1993) provided a vivid description of the anxiety and frustration caused by an over-zealous sensory bombardment of information leading to informational culture shock with:

Technology increases the available supply of information. As the supply is increased, control mechanisms are needed to cope with new information. When additional control mechanisms are technical, they further increase the supply of information. When the supply of information is no longer controllable, a breakdown in the psychic tranquility and social purpose occurs. Without defenses, people cannot find meaning in their experiences, lose their capacity to remember, and have difficulty imagining reasonable futures. (p. 72)

To many this information overload phenomenon is exhilarating; to others it is frightening, threatening, even paralytic (Borkovich, 2012b). For protection, people gravitate to like-minded groups where membership forms cultures and subcultures within organizations. Members find solace and security in communities of practice, learned behavior, and shared systems of meaning. Unfortunately, some organizations foster closed societies and entropic silos where information systems decline, deteriorate, and eventually collapse under their own weight.

\section{Infomania}

Originally coined by Ferrarini (1984), and subsequently defined by online dictionaries into popular parlance, infomania refers to an obsessive need to constantly check emails, texts, social media, online news, etc., often resulting in a declining ability to concentrate uninterrupted, concurrently lowering the floor for effective learning of life management skills. Endless distractions and the stress of information overload combine to perceptibly degrade the mental acuity of students and knowledge workers resulting in infomania. People are less capable of thinking, lack creativity and innovation, can neither solve problems, nor make decisions. A 2005 research study commissioned by Hewlett-Packard (Wilson, 2010) reported that IQ scores of knowledge workers tested while they were subjected to distraction and overload were reduced by 10 points; and subsequent to emails or other digital distractions took 23 to 30 minutes to restore cognitive awareness and concentration on the original task. Infomania derailed knowledge workers by causing them to work well below their full potential by producing less output, thinking superficially, and generating fewer new ideas, despite investing increased time (Hallowell, 2005).

\section{Digital Agility}

For the purposes of this paper, organizational agility refers to the application of digital technology to assist social media users and corporate professionals in the prosecution of their respective roles and responsibilities. The term 
agile emanates from Larman's (2004) software development process meaning rapid and flexible response to change, maneuverability, and iteration designed to meet the needs of the end-user. When referring to organizations' information systems, agility provides the path for constant, flexible, incremental and iterative improvement, including course correction and adaptation. The US Department of Defense (DoD) espouses that Information Age agility is an imperative to successfully cope with changes in circumstances in a dynamic environment (Alberts, 2011). In concert with DoD, corporations are in agreement that agile organizational management is required to control a dynamically agile information system. However, the Digital Age brought with it an illusion of power and control based upon technology, automation, and systems; and the misplaced belief that organizational culture would overcome all these information overload challenges (Atkinson \& Moffitt, 2007).

\section{Context Collapse}

Coined by Wesch $(2008 ; 2009)$, context collapse refers to an infinitely possible online audience contrasted to the limited groups a person normally interacts with face-to-face (Vitak, 2012). Context collapse resulted from a steady decline of traditional anthropological kinship relationships of family and close friends; rapid acceleration of online (and often anonymous) virtual relationships; and exacerbated privacy and security concerns regarding social media platforms and other types of information glut (Borkovich \& Breese, 2016a). Information abounds but meaning and connectivity are lost.

Web 2.0 advanced the user community into a virtual reality where ubiquitous internet participation is advocated and welcomed. Information is streaming live at break-neck speed with little regulation or oversight, and a vast opportunity exists to post subjective opinions in lieu of objective information. Postman (1993, p. 70) described "information appear[ing] indiscriminately, directed at no one in particular, in enormous volume and at high speeds, disconnected from theory, meaning, or purpose."

Facebook, faced its own organizational crisis of information overload following ten years of exponential growth in membership (Statista Online, 2016). By 2016, users could no longer routinely support their own personal bombardment of information from an increasing number of "friends." Facebook announced that context collapse was to blame and the cause of a decline in people sharing original, personal content, the fuel that powers the revenue generation at the heart of its social network (Efrati, 2016; Frier, 2016).

\section{The Pew Survey: Information Overload Report (December 2016)}

A recent Pew Survey (Horrigan, Dec. 2016) of 1,520 American adults (18 and older) reported that a large majority of Americans felt that information overload was not a problem. $20 \%$ stated they felt overloaded by information, a decline from the $27 \%$ figure from 2006 , while $77 \%$ stated they liked having lots of information at their fingertips. Two-thirds (67\%) reported that having more information at their disposal actually helped to simplify their lives. Surprisingly, the survey showed that most Americans were comfortable with their abilities to cope with information flows in their day-to-day lives. Moreover, those who owned multiple devices felt more capable of handling data; and those who were more likely to experience information overload had less technology, were poorer, less welleducated, and older. However, the demographic data collection did not identify and provide statistics for professional employees, such as knowledge workers and managers.

Not surprisingly, the greater the feeling that institutions expected people to gather too much information for transactional purposes, the more likely people stated they had problems with information overload. More than half $(56 \%)$ felt institutions like schools and corporations expected them to do too much information gathering in order to keep up with tasks; and stated that they felt stressed about the amounts of information they had to manage. In general, people managed information demands fairly well only when these demands came to them on their own terms. Pew further reported that when organizations expected too much information gathering from people, stress and anxiety were evident.

\section{Problem Statement: What is the current state of Organizational Information Overload?}

With all this expert logic, how could we not rationalize and manage this wonderful glut of information? But Simon (1972) pointed out that although all this data, information, and knowledge constantly contributed to our deeper understanding, humans were constrained and confined within our own individually "bounded rationalities" and were only capable of seeking, learning, retaining, remembering, extracting, and applying so much knowledge at any given time. Without overtly realizing it, we were "satisficing" (Simon, 1956), merely applying the portmanteau to our 
actions by using the best available information, not perfect or all-encompassing, to solve problems and make decisions in our daily lives. "Satisficing" suddenly re-entered the popular parlance among academics as the moniker associated with a coping mechanism meant to eliminate the excessive information chaos that clouded our judgment.

Successful organizations, comprised of earners, consumers, and information producers, are agile, aggressive, volatile, high-energy, fast-paced, and rapid-response. Many corporations strongly encourage their employees to engage in social media to promote its products and services, recruit employees, advertise its events and contests, and to solicit public good will, ever contributing to the infinite information glut and the potential loss of meaningful context in the workplace. Digital Age organizations all experience information overload from time to time, and this phenomenon has already reached critical mass for many. In hindsight, it is apparent that $20^{\text {th }}$ century computing advances all pointed to this inevitable phenomenon of $21^{\text {st }}$ century information glut.

\section{METHODOLOGY}

This qualitative study was an interpretative approach to inquiry that focused on adult professional employees of a Mid-Atlantic Subsidiary of Gotham Inc. For the purposes of this study, "Gotham" is a pseudonym employed to shelter the identity of a behemoth US Fortune 500 publicly-traded global business concern. Although quantitative topical survey studies abound, the research motivation was predicated upon noted gaps in the qualitative literature following the introduction of information overload and technical agility as emerging social-cultural constructs during the latter part of the $20^{\text {th }}$ and early $21^{\text {st }}$ century. Information Overload, in concert with organizational agility, had not been fully explored relative to Fortune 500 entities and deserved further attention. The interest was in determining the rationale behind information glut as it related to the corporate workplace; and the specific situations that arose when organizations imposed high information demands on its employees. This descriptive study explored how and why these phenomena occur, contrasted to the quantitative approach of what and how much.

\section{Agile Ethnography}

Unique to this study was the implementation of agile ethnography (Skovira, 2012; Borkovich, 2012a, 2012b, 2012c), a flexible, iterative, adaptive, course-correcting approach to qualitative inquiry. Advanced from Larman's (2004) agile approach to iterative software development, agile ethnography enables the researcher to quickly develop a facile working rapport with the organization because the role of participant-observer is embedded, allowing for immediate acceptance and indistinguishable identity. Rooted in traditional anthropology, agile ethnography is an interactive form of participant-observation implemented and bounded within the workplace. It evolved into a rapid, flexible, short-term, non-static research process designed to capture the multi-layered and matrixed social-cultural environments of a fluid business situation. The classic ethnographer required extensive time to learn the social-cultural environment and played the role of "outsider" until trust and acceptance was earned. But the Digital Age $21^{\text {st }}$ century requires an agile ethnographer to be an insider" with easy access, familiarity of the situation, and typically a de facto embedded researcher.

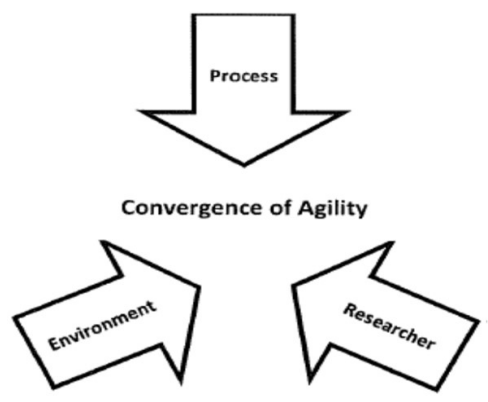

Figure 1. Agile Ethnography: Essential Intersecting Components. Copyright C D. J. Borkovich (2012a, p.8). Reprinted with permission

This study was encapsulated by the constraints of time, access, facility, location boundaries; interchangeable, overlapping, cross-cutting cultural groups; and a limited performance period, hence the moniker, agile ethnography. 
Figure 1 depicts the three converging components of a successful agile ethnography: 1). fluid process; 2). dynamic environment; and 3). an adaptable flexible researcher. Agile ethnography, when applied properly, solves this research dilemma by providing the same reliable, credible, valid, and transferable data as traditional ethnography; but with greater efficiency by intersecting the agility of the process, the environment, and the researcher toward the primary objective of providing quality and timely results. In the $21^{\text {st }}$ century, waiting months or years for a monograph or a report will no longer do.

\section{Sample Size, Research Question, and Rationale}

This agile ethnography was accomplished by an embedded researcher with prior knowledge of the organization, and did not require additional time to learn the inner-workings of the organization. This 90-day study was operationalized through participant-observation, interviews, and in-depth Informant conversations of a sample size of fifty-six professional and managerial employees $(n=56)$ within a facility population of 282 . The examined artifacts included a variety of laptops, tablets, hot-spots, mobile tech devices, and documentation.

The research question was directly posed to all Informants and interviewees alike: "Over the past ten years of professional employment, has your current expanded access to digital information simplified and decreased your workload, or has it complicated and increased your workload?" Subliminal queries and observations framed a twofold purpose to also discover: 1). How did employees manage perceived information overload in a digitally agile organizational environment? -and- 2). How did employees feel about implementing a corporate directive that mandated use of no-cost mobile tech devices, perceived to mitigate information glut?

The sample size was purposefully selected by identifying salaried professional employees and managers with a minimum of 10 years experience, representative of every department in this facility, and whose performance of their roles were designated as essential and integral to each professional discipline, department, customer deliverable, and to the success of the overall corporate mission. Table 1 illustrates the overall composition of the study.

Table 1. Corporate Composition of the Agile Ethnography

\begin{tabular}{|l|l|}
\hline Subject & Gotham Inc. (Subsidiary of a Publicly-traded Fortune 500 Global U.S. Company) \\
\hline Facility & Mid-Atlantic Location \\
\hline Population & 282 Employees $(100 \%)$ \\
\hline Sample Size & $\mathrm{n}=56$ Employees $(20 \%$ of Population) \\
\hline Informants & 8 \\
\hline Research Period & 90 Calendar Days \\
\hline
\end{tabular}

The semi-structured interviews encouraged the participants were encouraged to share information as their comfort levels allowed. Eight Informants willingly and eagerly volunteered information through unstructured conversations. Results were then analyzed and interpreted to further refine the findings, determine meanings, and develop future recommendations. Table 2 reflects the sample size demographics.

Table 2. Corporate Composition of the Sample Size

\begin{tabular}{|l|l|l|l|}
\hline \multicolumn{5}{|c|}{ Demographics } & Sample Size & $\begin{array}{l}\text { Total } \\
\mathbf{5 6}\end{array}$ & $\begin{array}{l}\text { Percentage } \\
\mathbf{1 0 0 \%}\end{array}$ \\
\hline Gender & Male & 36 & $64 \%$ \\
\hline & Female & 20 & $36 \%$ \\
\hline Age & Total & $\mathbf{5 6}$ & $\mathbf{1 0 0 \%}$ \\
\hline & $\geq 36$ Yrs. & 32 & $57 \%$ \\
\hline & $\leq 35$ Yrs. & 24 & $43 \%$ \\
\hline Job Category & Total & $\mathbf{5 6}$ & $\mathbf{1 0 0 \%}$ \\
\hline & Management & 34 & $60 \%$ \\
\hline & Professional & 22 & $40 \%$ \\
\hline Informants & Total & $\mathbf{0 8}$ & $\mathbf{1 0 0 \%}$ \\
\hline & Male & 04 & $50 \%$ \\
\hline & Female & 04 & $50 \%$ \\
\hline
\end{tabular}


To increase the credibility and quality of the data, the findings were triangulated by cross-comparing the elements of participant observations, Informant conversations, and examination of artifacts; and then ensured further validity by employing member checks with Informants and meeting participants to actively engage them in the process and to corroborate the field notes. Figure 2 depicts the iterative triangulation process.

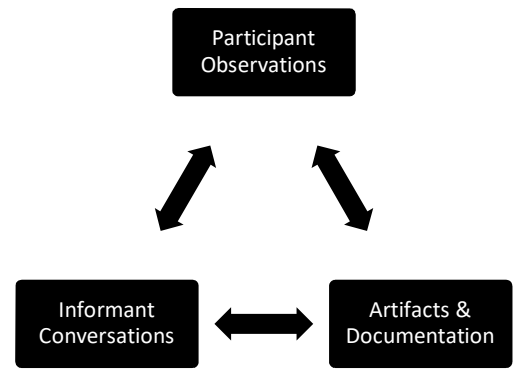

Figure 2. Iterative Triangulation Process. Copyright (C D. J. Borkovich (2012a, p.17). Reprinted with permission.

\section{DISCUSSION AND INTERPRETATION}

The question has long been posed: How do established traditional companies like one hundred twenty-six year-old Gotham successfully transform from a manufacturing giant to a knowledge-based information service provider? Gotham began this path following the transition from its former domestically jobs-driven CEO, to its new global off-shoring CEO in 2001. Seventeen years later, the company is still struggling with its shift in strategy and culture from a Six Sigma environment of energy, energize, edge, and execution (O'Boyle, 1998), to one of digital simplification, lean and fast principles, imagination, and agility.

The result was the establishment of a new subsidiary, Gotham Digital, to increase growth and scale with an evolutionary presence around the world. However, although the strategic change to a knowledge-based digital information culture was positive, negative decisions led to the sale of domestic manufacturing plants, massive American jobs loss, and the increase of global employees, products, and services. In the US, employees had to deal with an influx of over-abundant amounts of information from all over the world, different, often incompatible or obsolete ERP systems, contractual language and interpretation barriers, foreign laws, customs, and export/import regulations that were entirely unknown. Fewer US employees processed overwhelming amounts of global data with little appreciation, recognition, or a sense of value. The success of Gotham Digital remains unknown, as the CEO responsible for cloud-based platforms and the internet-of-things was fired and replaced in 2017 by a new leader whom accepted this daunting task to restore Gotham to its former glory.

On the positive side, Gotham responded to this new $21^{\text {st }}$ century global context and feedback by making agility and simplification the operating rhythm. Digital solutions in an increasingly inter-connected workplace, listening to the millennial workforce, and requesting employee engagement and feedback were also imperatives. The new cultural orientation changed from Core Values and Mission Statements to "Gotham Beliefs" to suggest that people changed their frame of thinking to the new way. The "Beliefs" reflected a renewed emphasis on acceleration, agility, lean to go fast, and customer focus. Interestingly, the "Beliefs" were crowd-sourced from the employees representing an agile approach to secure buy-in and capture new internal and external information (Krishnamoorthy, 2015).

\section{Observations and Analyses}

Field notes recorded disintegrating relationships between employees and employers due to the increased level of information overload and longer work hours. Also evidenced was the increased level of risk that employees were willing to take to perform personal business at work, fostered by a digital knowledge environment that mandated its employees to be always on. Employees expressed that company-mandated mobile tech devices required multitasking, particularly by those employees that followed the company rules to utilize work devices only for work purposes. Some employees recognized and accepted a form of company normative control (Kunda, 2006) and opted to use only personal devices for personal business. Therefore, those rule-bound employees also carried personal smart phones, laptops, tablets, and hot spots for non-work-related purposes requiring a more focused propensity for 
multi-tasking. Since the rule to use company-provided equipment only for business-related tasks was not enforced, the employees strongly believed that company tacitly encouraged that work equipment also be used for personal business, since this would necessitate that both the equipment and the employee were always on 24/7/365.

For example, during evenings, weekends, holidays, and vacations, if an employee checked the company iPhone for work emails and texts, he/she would typically check personal email and text accounts, as well. Furthermore, corporate rule enforceability would be difficult because everyone knew that senior management also used work devices during worktime for personal business, too. It was a well-known double standard that no one would be fired for using a company tech device for personal business; however, if the company had another reason to get rid of an employee, the use of company devices and worktime for personal business would be documented in the personnel file as extrinsic evidence representing an additional rationale to fire the employee. This phenomenon contributed to widespread infomania (Ferrarini, 1984), the obsessive need to constantly check emails, texts, social media, online news, etc., often resulting in a needless waste of time and a declining ability to concentrate uninterrupted.

Employees were encouraged to extemporaneously offer opinions; however, only one identical question was posed to jump-start the conversation: "Over the past ten years of employment, has your current expanded access to digital information simplified and decreased your workload, or has it complicated and increased your workload?" An overwhelming number of replies (98\%) were a resounding, "Increased!' Table 3 depicts the participants' demographics followed by a limited selection of summarized comments from the interviews.

Table 3. Interviewee Results - Response Sampling

\begin{tabular}{|c|c|}
\hline $\begin{array}{c}\text { Adult } \\
\text { Interviewees }\end{array}$ & $\begin{array}{l}\text { Q: Over the past ten years of employment, has your current expanded access to digital } \\
\text { information simplified and decreased your workload or has it complicated and increased your } \\
\text { workload? }\end{array}$ \\
\hline \multirow[t]{3}{*}{$\begin{array}{c}\text { Males } \\
(36=64 \%)\end{array}$} & $\begin{array}{l}35 \text { Males replied "Increased and Overloaded" to this question. One (1) male ( } \geq \mathbf{3 5}) \text { replied that } \\
\text { "online communications keeps me us wired to work and to others } 24 / 7 \text {, and I like the option to jump } \\
\text { from work data to personal data in the space of a second. I can work anywhere, even in Starbucks!" }\end{array}$ \\
\hline & $\begin{array}{l}\text { M7 ( } \geq 35) \text { : "No, tech has not decreased my workload - just the opposite! The emails, attachments, } \\
\text { Jabbers, Colabs, WEBEXes, text messages never stop and sometimes I just take a walk because I } \\
\text { feel bombarded and can't stop or slow down the communications. The more tech I have, the more } \\
\text { info I receive. I can never catch up and I can't seem to turn the tech off or myself off! What used to } \\
\text { be fun and challenging is not anymore and keeping up with the deluge of information is } \\
\text { impossible!" }\end{array}$ \\
\hline & $\begin{array}{l}\text { M5 ( } \leq 36) \text { : "Does tech make me more agile - NO! I like spending time with my friends on weekends } \\
\text { and holidays. Now I'm tethered to mobile devices, and just because Gotham pays full freight, my } \\
\text { off-work time is no longer my free time. My buddies think I'm crazy to stay at this job and they may } \\
\text { be right." }\end{array}$ \\
\hline \multirow{3}{*}{$\begin{array}{c}\text { Females } \\
(20=36 \%)\end{array}$} & All 20 Females replied "Increased and Overloaded" to this question. \\
\hline & $\begin{array}{l}\text { F6 ( } \leq 35) \text { : "We always get new laptops, iPhones, hotspots, tablets, monitors, docking stations to take } \\
\text { home, and anything else we want. At first we were thrilled and believed all this tech equipment } \\
\text { would eliminate the stress for the work we had to process. Gotham pays our monthly statements and } \\
\text { we don't see them unless we are queried about a strange-looking line item that has to be explained. } \\
\text { Because Gotham pays for everything and doesn't mind if we work remotely. But I am constantly } \\
\text { overloaded with work and feel responsible to be available all the time. I don't like it, but that's the } \\
\text { way it is." }\end{array}$ \\
\hline & $\begin{array}{l}\text { F3 }(\geq 36) \text { : "I need a work-life balance and I don't get this at Gotham. My children are in school with } \\
\text { lots of events and I can't be bothered every evening with a vibrating phone and beeps with text } \\
\text { messages. No, my life is definitely not simpler, it's more complicated! And every time a lay-off is } \\
\text { announced, the workers aren't replaced which means more work for the rest of us!" }\end{array}$ \\
\hline $\begin{array}{c}\text { Total }=56 \\
(100 \%)\end{array}$ & $\begin{array}{l}\text { Results: } 98 \% \text { ( } 55 \text { participants) of the Gotham sample size perceived that Information } \\
\text { Overload in the workplace complicated and increased their workloads, and exacerbated their } \\
\text { stress and anxiety levels. }\end{array}$ \\
\hline NOTE: & $\begin{array}{l}\text { Only one male from the } \leq 35 \text { Age Group expressed that the increased agile technology provided by } \\
\text { the company at no-cost increased productivity and alleviated some information overload because } \\
\text { data could be immediately deleted. }\end{array}$ \\
\hline
\end{tabular}


Although every Gotham operating rhythm mandated agility, responsiveness, flexibility and focus, observations and Informant interviews of US employees evidenced a very different scenario. Employee frustration with information overload performed by fewer workers over longer hours resulted in apathy and negativity despite the unlimited nocost tech resources of mobile devices, laptops, monitors, telepresence equipment, WEBEX, Internet, social media access, VPNs, hot-spots, iPhones, and the ability to telecommute via Gotham apps.

Gotham was known to have vast financial, technical, and human resources, with no shortage of cybersecurity, training programs and digital equipment of every ilk. However, this research focused on determining employee feedback to ascertain whether or not these agile corporate strategies were helping or hindering productivity due to an overwhelming influence and constant daily bombardment of disparate information from multiple sources. Management erroneously expected that assigning multiple mobile digital devices would provide employees the agile process to cope with the frustration and shock of information overload. Despite the abundant digital resources, nocost technical equipment and siloed protected culture, employees were willing to risk loss of income, firing, and public humiliation to salvage perceived lost or cheated personal time taken by the employer due to constant information glut. Figure 3 depicts an individual's experiences with Information Glut and the obstacles and challenges that must be overcome.

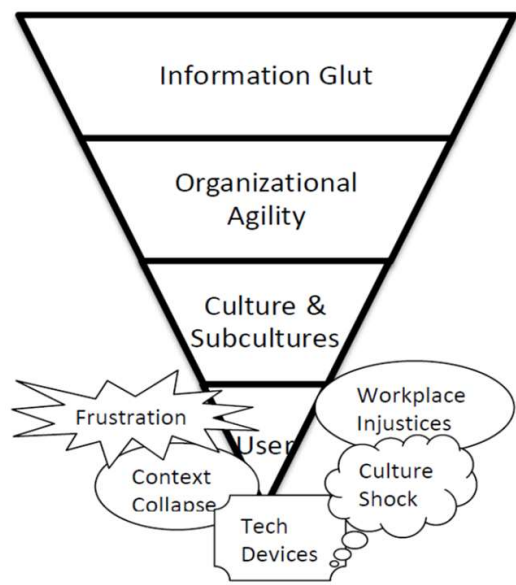

Figure 3. User's Experiences with Info Overload. Copyright (C D. J. Borkovich (2017, p.153). Reprinted with permission

By comparison, a prior Gotham study (Borkovich, et al., 2016b) evidenced similar results of information overload by observing employees at every level spending increasing amounts of non-productive time (personal business) disguised as productive work time. An earlier Gotham study (Borkovich, 2012c) causally related information overload to a resultant paralytic culture shock in the organization. Findings indicated that the culture shock experienced by US employees performing more work with less people over longer hours resulted in the erosion of trust and loyalty, further exacerbated by the employer's mandated requirement to tether its employees to mobile digital technology. Many employees viewed this employer tactic of disregarding earned and accrued leave, weekends and holidays as insensitive and unfair, and critically expressed their opinions of management as unjust treatment. Informants reported that personal business usage by some disgruntled employees ran as high as $30-50 \%$ of each work day as employees covertly retaliated against big brother.

Over the past 10 years, Gotham publicly portrayed agile technology as ameliorators to information overload and a cure-all to frustrated employees. But interviewees differed in their experiences and interpretations. Results showed that professionals and managers alike suffered overwhelming information glut and culture shock that manifested into context collapse and workplace social injustices (Anteby, 2008; Nadisic, 2008) that exacerbated tension, anxiety, and depression. Figure 4, "Organizational Agility Process," depicts the flow of organizational information manifested by agile digital devices resulting in workplace glut, culture shock, context collapse, and social injustices. 




Figure 4. Organizational Agility Process Results. Copyright (C D. J. Borkovich (2017, p.154). Reprinted with permission

Turkle (2011, p. 295) argued that when we are overwhelmed by an influx of data, "we expect more from technology and less from each other," drawing us to digital solutions that are convenient and speedy. Since Gotham's agile edict continues to mandate unlimited tech devices intended to mitigate or ameliorate information overload, the only way to break this cycle of frustration and covert behavior may be to strike a balance between the perceived benefits of always on technology and the comfort and safety of employee personal time when the devices can be turned off.

\section{Comparison to the Pew Information Overload Survey}

Contrary to the results of the Pew Survey (Horrigan, Dec. 2016), Gotham's agile ethnography reflects that $98 \%$ of its sample size reported that information overload perpetuates in an agile organizational environment, even one with extraordinary digital, technical, financial, and economic resources and advantages. Although Pew reported that only $20 \%$ felt overloaded by information, while $77 \%$ liked having so much information at their fingertips, it is important to note the following divergent factoids from its report.

Pew quantitatively surveyed 1,520 US adult Americans, aged 18 or older, living in the US, and interviewed via landline or cell phones in English and Spanish. Pew's objective was not to deliberately elicit responses from corporate knowledge workers and managers, but instead focused on a cross-section of Americans with access to the Internet and multiple mobile tech devices. Pew was also interested in economic status, age, gender, and level of education, but not careers, disciplines, and employment positions. Pew's perspective was to solicit user data about perceptions of information overload relating to how society accesses knowledge, facilitates connections with friends, uses social media, and transacts e-commerce. Therefore, it is this researcher's opinion that the Pew data and the findings of this specific Gotham study do not positively correlate.

\section{LIMITATIONS AND FUTURE APPLICATIONS}

This particular study had a number of limitations that need addressed. The research was focused on one large global subsidiary in the Mid-Atlantic US, and the participants were all professional or managerial adults residing exclusively within that location. Future research would benefit from a larger sample size in other US locations, as well as comparisons to smaller businesses and entrepreneurial firms. Additionally, the findings of this exploratory study indicate that future qualitative inquires warrant a larger data pool to generate hard validity and transferability of results. Other challenges associated with digital knowledge-based workplace studies included obtaining the cooperation, willingness, and honesty of participants to reveal opinions on a sensitive workplace topic; however, large-scale quantitative research could implement anonymous methods toward a potential generalization of data.

This researcher's interpretations suggested that corporate management is not yet sure how to handle this paradigm shift from hard copy document control to digital data information overload; therefore, it is further recommended that future studies incorporate systems theory, cultural, and business management research to address the need to understand and shape the organizational impact, influence, and the perceived usefulness of agility and simplification in a digital environment. Information systems engineering may also realize a structured approach to remedy the intangibles of data glut related to employee behavior, by easing innovation processes and ameliorating the 
information overload frustrations relating to mandated digital equipment and mobile tech devices requiring knowledge-workers to be always on 24/7/365.

\section{CONCLUSION}

This purpose of this study was to ascertain if the state of information overload in the workplace had improved or regressed over the prior decade. The underlying theme was also to learn how employees managed perceived information overload; and, how did employees feel about mandated use of no-cost mobile tech devices to mitigate information glut? Interviews and observations furthered our exploratory research when participants posed even more unanswered questions, such as: How can employees achieve a work-life balance in the digital workplace? Is it even possible? Do we really want free mobile tech devices when we have to be available, engaged, and connected $24 / 7 / 265$ ? Is the information overload stress and anxiety so great that some knowledge workers want different nondigital careers? We can permit ourselves to be overwhelmed by massive amounts of data and information, or we can choose to be emboldened by its possibilities. Digital Age organizations all experience information overload from time to time, but this phenomenon has already reached critical mass for many.

From this limited study we learned that digital, agile, mobile tech devices and telecommuting did not help employee management of information overload. On a small scale, this study confirmed the theories of several academics, social scientists, and technical experts that information glut exists in the workplace; but agility and mobile tech devices do not always mitigate the challenges presented by the overwhelming and constant overload of information. It was further discovered that other contributing factors, such as increased concern about lack of privacy; loss of security regarding personal information; and distrust of the employer-employee relationship influenced the containment of digital information overload and its relative successful or unsuccessful management. This research discovered that many professional employees also experienced infomania, context collapse, culture shock, and workplace injustices from the constant bombardment of overwhelming amounts of information arriving at breakneck speed due to various uncontrollable digital collection points. Erroneously identified as the perceived liberators of information glut, implementation of tech agility and simplification processes remained challenges for management.

Furthermore, we learned blurred boundaries existed between professional and personal responsibilities due to the use of company-mandated tech devices complicated by the requirement to be available and always on 24/7/365. The researcher deduced that many adults are no longer willing to sacrifice their personal health, well-being, time off-theclock, privacy, trust, reliability, credibility, salary, bonuses, and career potential in exchange for unlimited use of company digital equipment, software, hardware, mobile tech devices, and the privilege of telecommuting. Use of free tech is not always a fair trade for managing an ever-increasing amount of information glut.

While technology is neutral, people are not (Schmidt \& Cohen, 2013). Connectivity can and will help upend power imbalances, expose corruption and other malevolent forces, and support free-flowing information. However, this study evidenced a darker side of corporate information overload, exacerbated not mitigated, by agile tech devices, resulting in knowledge workers' inability to process work efficiently. As the lines continue to blur between professional and private lives due to longer hours required to keep up in the digital workplace, other remedies in addition to agility, must be pursued to achieve a healthy, happy, and successful work-life balance. At times, when companies fall short in their remedies, the failure may not be in those doing their jobs, but the fault of management for not reading the culture correctly and making adjustments. This study showed that corporate digital agility and free mobile tech devices are not always panaceas to workplace information overload.

\section{REFERENCES}

Alberts, D. S. (2011). The agility advantage: A survival guide for complex enterprises and endeavors. Washington, D.C.: CCRP Publication Series.

Anteby, M. (2008). Moral gray zones: Side productions, identity, and regulation. Princeton: Princeton Univ. Press. Atkinson, S. R., \& Moffat, J. (2007). The agile organization: From information networks to complex effects and agility. Herndon, VA: CCRP Publication Series. 
Berners-Lee, T. (2000). Weaving the web: The original design \& ultimate destiny. London: Harper Collins.

Borkovich, D. J. (2012a). Agile ethnography: A qualitative methodology for the $21^{\text {st }}$ century. Robert Morris University CIS Convergence Journal, 1(1), 1-20.

Borkovich, D. J. (2012b). The influence of nationalistic cultural behavior in the workplace (Doctoral dissertation). Available from ProQuest Dissertations and Theses database. (UMI No. 3504088)

Borkovich, D. J. (2012c). When corporations collide: Information overload. Issues in Information Systems, 13(2), 269-284.

Borkovich, D., \& Breese, J. (2016a). Social media implosion: Context collapse! Issues in Information Systems, 17(4), 167-177.

Borkovich, D. J., Skovira, R. J., Kohun, F., \& Breese, J. (2016b). La perruque in the American digital workplace: Stealing company time. Issues in Information Systems, 17(3), 176-186.

Borkovich, D. J., \& Skovira, R. J. (2017). Empowering employees with digital agility: Mitigation strategies for information glut. Issues in Information Systems, 18(4), 146-157.

Carr, N. (2010). The shallows: What the internet is doing to our brains. New York: Norton \& Co.

Chen, B. X. (2011). Always on: How the i-phone unlocked the anything-anytime-anywhere future-and locked us in. Cambridge, MA: Da Capo Press.

Efrati, A. (2016, April 7). Facebook Struggles to Stop Decline in 'Original' Sharing. The Information Online. Retrieved from: https:/www.theinformation.com/facebook-struggles-to-stop-decline-in-original-sharing

Ferrarini, E. (1984). Confessions of an infomaniac. Indianapolis: Sybex, a Wiley Company.

Frier, S. (2016, April 7). Facebook wants you to post more about yourself. Bloomberg Online. Retrieved from: http://www.bloomberg.com/news/articles/2016-04-07/facebook-said-to-face-decline-in-people-posting

Gross, B. M. (1964). The managing of organizations: The administrative struggle. New York: The Free Press.

Hallowell, E. M., (2005). Overloaded circuits: Why smart people underperform, Harvard Business Review (Jan. 2005), 54-62.

Hardy, Q. (2016, March 14). As a data deluge grow, companies rethink storage. New York Times Online. Retrieved from: http://www.nytimes.com/2016/03/15/technology/as-a-data -deluge-grows-companies-rethink-storage.html

Krishnamoorthy, R. (2015). GE's culture challenge after Welch and Immelt. Harvard Business Review Online (January 26, 2015). Retrieved from: https://hbr.org/2015/01/ges-culture-challenge-after-welch-and-immelt

Heim, M. (1990). Infomania. In C. Ricks \& L. Michaels (Eds.), The state of the language (pp. 300-306). Berkeley: University of California Press.

Horrigan, J. B. (2016). Information Overload. Pew Internet \& American Life Project Report, December 7, 2016. Retrieved from: http://www.pewinternet.org/2016/12/07/information-overload/

Kumar, S. (2015, July 10). 5 Common problems faced by e-learners. Retrieved from: https://elearningindustry.com/5-common-problems-faced-by-students-in-elearning-overcome

Kunda, G. (2006). Engineering culture: Control and commitment in a high-tech corporation (2 ${ }^{\text {nd }}$ ed.). Philadelphia: Temple University Press. (Original work published 1992) 
Larman, C. (2004). Agile and iterative development. Boston: Addison-Wesley.

McGinnis, P. (2016). The 10\% entrepreneur: Live your startup dream job. New York: Penguin.

Nadisic, T. (2008). The Robin Hood effect: Antecedents and consequences of managers using invisible remedies to correct workplace injustice. In Gilliland, S. W., Steiner, D. D., \& Skarlicki, D. P.(Eds.). Justice, morality, and social responsibility of business (pp. 125-153), Charlotte, NC: Information Age Publishing, Inc.

O’Boyle, T. F. (1998). At any cost: Jack Welch, GE, and the pursuit of profit. New York: Vintage Books.

Oberg, K. (1960). Culture shock: Adjustment to new cultural environments. Practical Anthropology, 7, 177-182.

Postman, N. (1993). Technopoly: The surrender of culture to technology. New York: Vintage Books.

Przybylski, A. K. (2013). Motivational, emotional, and behavioral correlates of fear of missing out. Computers in Human Behavior, 29, 1841-1848.

Schmidt, E., \& Cohen, J. (2013). The new digital age: Reshaping the future. New York: Random House.

Shannon, C., \& Weaver, W. (1949). The mathematical theory of communication. Chicago: Univ. of Illinois Press.

Simon, H. A. (1956). Rational choice and the structure of the environment. Psychological Review, 63(2), 129-138.

Simon, H. (1972). Theories of bounded rationality. In C. B. McGuire \& R. Radner (Eds.), Decision and Organization (pp. 161-176). Amsterdam: North-Holland Publishing Co.

Skovira, R. J. (2012). Agile ethnography: A re-imaging of ethnography for use in organizational life. Department of Computer Information Systems, School of Communications and Information Systems, Robert Morris University, Moon Township, PA. [Unpublished manuscript]

Statista Online. (2016). Number of monthly active Facebook users worldwide 2016. Statista - The Statistics Portal. Retrieved from: http:/www.Statista.com/statistics/264810/number-of-monthly-active-facebookusers/worldwide

Toffler, A. (1970). Future shock. New York: Random House.

Toffler, A. (1981). The third wave. New York: Bantam Books.

Turkle, S. (2011). Alone together: Expecting more from tech and less from each other. New York: Basic Books.

Vitak, J. (2012). The impact of context collapse and privacy on social networks. J. Broadcast Media, 56, 451-470.

Wesch, M. (2008, July 31). Context collapse. Digital Ethnography at Kansas State University. Retrieved from: http://mediatedcultures.net/youtube/context-collapse/

Wesch, M. (2009). YouTube \& you: Experience of context collapse self-awareness. Explorations of Media, 8(2), 1934.

Wilson, G. (2010). Clarifications to Infomania 2005 Experiment for H-P. Retrieved from: http://www.drglennwilson.com/Infomania_experiment_for_HP.doc 